\title{
Controlled free radical polymerization of vinyl acetate with cobalt acetoacetonate
}

\author{
MOHAMMAD ALI SEMSARZADEH* and SAHAR AMIRI \\ Chemical Engineering Department, Polymer Group, Tarbiat Modares University, \\ P.O. Box: 14155/143, Tehran, Iran \\ e-mail: semsarzadeh@modares.ac.ir
}

MS received 28 June 2011; revised 23 September 2011; accepted 28 October 2011

\begin{abstract}
The polymerization of vinyl acetate with the complex catalyst of cobalt acetoacetonate [Co (acac $)_{2}$ ] and DMF ligand with benzoyl peroxide initiator has been successfully carried out in bulk and in solution. The bulk polymerization has been used in a new route consisting of a one-step polymer formation in a fine capillary tube. In this process, the high rate of propagation was used to carry out the reaction in a microcapillary tube. Under $60^{\circ} \mathrm{C}$, the colour-free reaction without solid catalyst impurity was $95 \%$ complete within a few hours. The high molecular weight of polyvinyl acetate (PVAc) with its relatively low molecular distribution without unreacted monomer provided a new method in microprocessing of the controlled radical polymerization of vinyl acetate in a one-step polymerization process. PVAc polymerization systems showed induction time, which was reduced in this reaction with using complex of $\mathrm{DMF} / \mathrm{Co}(\mathrm{acac})_{2}$. The kinetics of the reaction with a smaller degree of branching from this catalyst indicated that the electronegativity of the transition metal and diffusion of the homogeneous catalyst with DMF are important factors of fast polymerization in the bulk. Thermal properties of the polymer indicated a lower glass transition state. The easily reformed or stretched microsolid polymer demonstrated $20 \%$ crystallinity.
\end{abstract}

Keywords. $\mathrm{Co}(\mathrm{acac})_{2}$ catalyst; DMF ligand; bulk polymerization of vinyl acetate; capillary tube; controlled free radical polymerization.

\section{Introduction}

Polyvinyl acetate is a highly consumed polymer used in plastics and textile industry. The environmentally friendly polyvinyl alcohol produced from hydrolysis of this polymer is biodegradable and have found many applications in coatings, paper, and drug industries. In recent years, polyvinyl acetate with a well defined structure has been reported to be used in block copolymers and in the controlled radical polymerizations (CRP). In this process the unreacted vinyl acetate monomer is activated in telomerization reaction with chloroform to make a halogenated oligomer in the atom transfer radical polymerization (ATRP) with acrylates and styrene. ${ }^{1}$ The controlled radical polymerization of vinyl acetate monomer is reported to be difficult. ${ }^{2}$ The facile termination and chain transfer of vinyl acetate makes control of vinyl acetate polymerization difficult. However, a higher degree of control has been reported by us earlier. ${ }^{3}$ We have reported that the radical polymerization of vinyl acetate monomer in solution is stabilized

*For correspondence with triethyl amine to produce a higher yield of polymer with a lower molecular distribution. ${ }^{2,3}$ Since then, the prospect to utilize a transition metal catalyst with electron-donor ligands to increase the reactivity of the monomer in a controlled radical polymerization with new applications has been renewed. The currently produced vinyl acetate from the controlled polymerization reactions is strongly hampered by the catalyst impurity, low yield level, and unreacted monomers. The expensive initiators and solvents seem to be the main reasons. The expensive separation and purification processes are needed in larger scales. ${ }^{4}$ In this study, we report the facile and high yield reaction of vinyl acetate with $\mathrm{Co}(\mathrm{acac})_{2}$ catalyst, with DMF ligand and benzoyl peroxide initiator in the bulk. The facile reaction in bulk is $50 \%$ complete within a few minutes. The synthesis of the complex from ligand and $\mathrm{Co}(\mathrm{acac})_{2}$ catalyst and its use in the polymerization system of PVAc led to induction time in the beginning of the reaction. ${ }^{5-7} \mathrm{In}$ the current study, we used DMF ligand and $\mathrm{Co}(\mathrm{acac})_{2}$ directly in the polymerization and reduced the induction time, which led to faster reaction. In this reaction, the complex catalyst $\mathrm{Co}(\mathrm{acac})_{2} / \mathrm{DMF}$ forms an active catalyst that activates monomer radicals in a controlled 


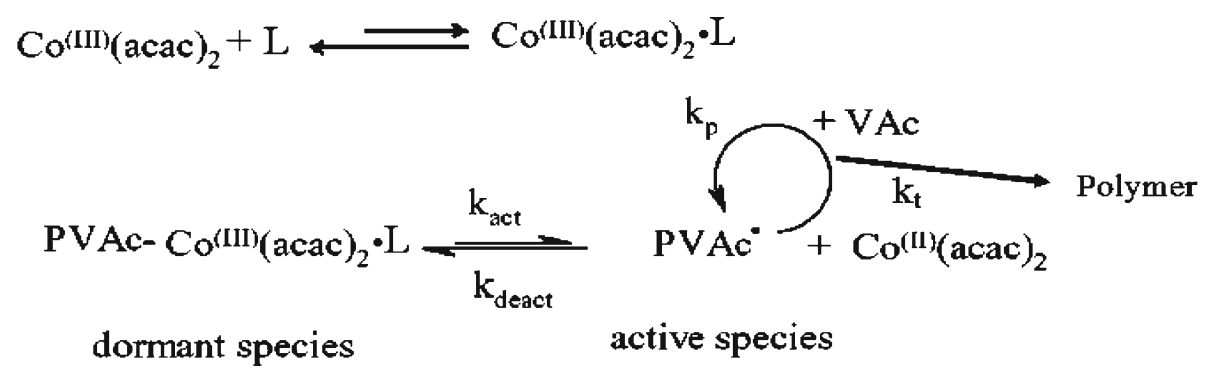

Scheme 1. Mechanism of the stabilized radical controlled polymerization of vinyl acetate.

radical polymerization and increases its conversion rate to $95 \%$ with a relatively low molecular weight distribution. Contrary to what has been reported recently, the complex catalyst starts the reaction without any lengthy induction time and the reaction is complete within hours. ${ }^{5-7}$ The reported synthesis of polyvinyl acetate at low temperature in solution is very long or about 300 days. ${ }^{8,9}$ The reaction mechanism suggested for the fast and controlled reaction is a stabilized freeradical controlled polymerization mechanism (SFRP) consisting of three steps:

(i) Equilibrium complex formation of catalyst with DMF ligand.

(ii) Growth step from the active monomer radical.

(iii) Termination step.

In scheme 1. kp, kact, kdeac and kt are kinetic constants related to propagation, activation, deactivation and termination rate constant and $\mathrm{L}$ is ligand (DMF).

The molecular weight distribution of polyvinyl acetate reported in radical polymerization is very broad (MWD > 3.0). ${ }^{3}$ The branching reaction from the cobalt acetoacetonate catalyst with DMF ligand is about $12 \%$. The branching percentage of the reaction with $\mathrm{ZnCl}_{2} /$ DMF catalyst was found to be around $27 \%$. Apart from the broad molecular weight distribution of polyvinyl acetate in the radical polymerization, the free radical polymerization of vinyl acetate in solution strongly depends on the solvent. ${ }^{3,8}$ According to density function theory or DFT, ${ }^{8}$ we have considered the electronegativity of $\mathrm{Co}, \mathrm{Sn}$, and $\mathrm{Zn}$ transition metals as simple estimates for the reactivity of $\mathrm{Co}(\mathrm{acac})_{2}, \mathrm{ZnCl}_{2}$, and $\mathrm{SnCl}_{2}$ catalysts used in the bulk polymerization of vinyl acetate. The catalyst with DMF ligand activates the monomer and stabilizes the radical (reaction 3 in scheme 1). Apart from the higher yields and low molecular distribution, the lower branching was considered important in the controlled free-radical polymerization of vinyl acetate. ${ }^{2,4,9,10}$ Other transitional metal catalysts like $\mathrm{ZnCl}_{2}$ and $\mathrm{SnCl}_{2}$ with DMF ligand doubled the degree of branching of the polymer. The facile reaction of vinyl acetate with conversion rate of $50 \%$ within a few minutes with $\mathrm{Co}(\mathrm{acac})_{2}-\mathrm{DMF}$ catalyst suggested a new alternative route to explore a micropolymerization reaction of vinyl acetate in a one-step reaction in a capillary tube. The low glass transition temperature of polymer formed in this process and the lack of solvent strongly suggested that diffusion of the homogeneous catalyst in the bulk is higher than that in solution. ${ }^{11}$ Apart from the diffusion, ionization and solvent effects will slow down the reaction in the solution. The reaction in bulk is therefore vastly different from the reaction reported in the solution. ${ }^{11}$ The longer induction time reported for the solid catalyst complex, and the time needed to dissolve the catalyst makes the reaction slower in the solution. ${ }^{3,5}$ In this paper, we have used the fast diffusion of catalyst to introduce a micropolymerization reaction in the capillary tube.

\section{Experimental}

\subsection{Materials}

Vinyl acetate (VAc) (Merck, >99\%) was dried over calcium hydride, distilled under argon, and stored under argon. Benzoyl peroxide (BPO), DMF(dimethylformamide), Co $(\mathrm{acac})_{2}$, methanol (Merck, >99\%) were used as received from Merck.

\subsection{Characterization}

${ }^{1} \mathrm{H}$ NMR spectra were recorded with a Bruker DRX 500 spectrometer $(500 \mathrm{MHz})$ in deuterated chloroform. Infrared spectra were recorded with a Bruker IFS 48 FTIR spectrometer. Molecular weight and its distribution (MWD) were recorded with a Waters 150C PScalibrated GPC in THF at $35^{\circ} \mathrm{C}$ and $1 \mathrm{~mL} / \mathrm{min}$ equipped with a refractive index detector and 104, 103 and $500^{\circ} \mathrm{A}$ set of ultrastyrogel columns. Differential scanning calorimetery (DSC) analysis were recorded with a Pyris 1 instrument at a heating rate of $10^{\circ} \mathrm{C} / \mathrm{min}$ under nitrogen atmosphere in the range of -20 to $300^{\circ} \mathrm{C}$. 
2.2a Bulk polymerization of vinyl acetate with $\mathrm{Co}(\text { acac })_{2}$ catalyst/DMF ligand/BZPO: DMF, $\mathrm{Co}(\mathrm{acac})_{2}$, and BZPO were added to the test tubes degassed with argon. Vinyl acetate was then added with a syringe under argon. The mixture was stirred and heated at $60^{\circ} \mathrm{C}$ for 10 to $480 \mathrm{~min}$ ). After the reaction, the mixture was diluted in methanol, (re)precipitation in an ice/water mixture, and filtered and dried in vacuum. The solvent and unreacted monomer was then removed under vacuum. The dried polymer products were analysed with GPC and ${ }^{1} \mathrm{HNMR}$. The monomer conversion was determined by weighing the polymer collected upon removal of unreacted monomer in vacuum at $50^{\circ} \mathrm{C}$ (table 1$){ }^{3}$

2.2b Bulk polymerization of vinyl acetate in $\mathrm{Co}(\text { acac })_{2}$ catalyst/DMF ligand in a capillary tube: DMF, $\mathrm{Co}(\mathrm{acac})_{2}$, and BZPO were added to the test tubes under argon. Vinyl acetate was then added with a syringe. The mixture was stirred and heated at $60^{\circ} \mathrm{C}$ for $10 \mathrm{~min}$, then transferred into capillary glasses (height: $10 \mathrm{~cm}$ and diameter: $5 \mathrm{~mm}$ ) with a syringe and placed at $60^{\circ} \mathrm{C}$. The mixture became viscose after one hour. After $72 \mathrm{~h}$, polyvinyl acetate-free monomer was removed from the capillary glass. The solid polymer tube was separated. The solvent and unreacted monomer was then removed under vacuum. The formed tube is a stable structure, which is free of monomers or any catalyst impurity or colour. ${ }^{3}$

2.2c Solution polymerization of vinyl acetate with $\mathrm{Co}(\text { acac })_{2}$ and BZPO in DMF solution: DMF, $\mathrm{Co}(\mathrm{acac})_{2}$, and BZPO were added to the large test tubes and degassed with argon. Vinyl acetate was then added with a syringe under argon. The mixture was stirred and heated at $60^{\circ} \mathrm{C}$ at various times. After a few hours, the solution changed from purple to a dark green viscose solution. The mixture was then diluted in methanol ( $5 \mathrm{mmol}$ ), and (re)precipitation in an ice/water mixture, the solvent and unreacted monomer were then removed under vacuum. The structure of polyvinyl acetate was analysed by GPC and ${ }^{1} \mathrm{HNMR}$. Monomer conversion was determined by weighing the polymer collected upon removal of unreacted monomer in vacuum at $50^{\circ} \mathrm{C}$ (table 1). ${ }^{3}$

\section{Results and discussion}

\subsection{Kinetics of reaction}

The kinetics of polymerization of vinyl acetate with the complex catalyst of $\mathrm{Co}(\mathrm{acac})_{2}$ and DMF ligand with benzoyl peroxide initiator was studied at $60^{\circ} \mathrm{C}$. The conversion of polymer in bulk indicated that the plots of $\operatorname{Ln}[\mathrm{M}]_{0} /[\mathrm{M}]$ versus time is linear (figure 1 ). The apparent propagation rate constant $\left(\mathrm{k}_{\mathrm{p}}^{\mathrm{app}}\right)$ was estimated from the slop of $\operatorname{Ln}[\mathrm{M}]_{0} /[\mathrm{M}]$ versus $\mathrm{t}$. from Equation (1).

$$
\operatorname{Ln}\left(\frac{[M]_{0}}{[M]}\right)=k_{p}\left[P^{0}\right] t=k_{p}^{a p p} \times t .
$$

The apparent propagation rate constant $\left(\mathrm{k}_{\mathrm{p}}^{\mathrm{app}}\right)$ of $0.4316 \times$ $10^{3}$ was calculated in bulk (table 1). The concentration of the active species calculated from the rate equation in solution is about 10 times lower than that of the bulk. The lower radical species in the solution was related to the higher diffusion rate and its reactions in the solution. Figure 1 shows the linear reaction of vinyl acetate monomer in the controlled radical polymerization in the bulk. All the vinyl acetate polymerization include induction period. In our suggested polymerization route, only a very short induction period was observed and the time dependency of the $\ln [\mathrm{M}]_{0} /[\mathrm{M}]$ function is not linear at higher values. Thus, both linearity in the kinetics and dependence of the molar mass on the monomer conversion may be explained by the change in the number of growing chains along the polymerization. In order to provide additional supporting evidence, the VAc polymerization was initiated from a low molecular weight cobalt (III)

Table 1. Calculated apparent propagation rate constant under steady-state free radical concentration for polymerization of VAc in bulk and solution systems with BPO initiator at $60^{\circ} \mathrm{C}$.

\begin{tabular}{lccc}
\hline Reaction & Polymerization system & $\mathrm{k}_{\mathrm{p}}^{\mathrm{app}}\left(\times 10^{-3} \mathrm{~s}^{-1}\right)^{\mathrm{a}}$ & {$\left[\mathrm{P}^{\circ}\right]\left(\times 10^{-7} \mathrm{M}\right)^{\mathrm{b}}$} \\
\hline 1 & Bulk & 0.4316 & 3.197 \\
2 & Solution & 0.0498 & 0.3689 \\
\hline
\end{tabular}

$[\mathrm{VAc}]_{0} /[\mathrm{Co}]_{0} /[\mathrm{BPO}]_{0} /[\mathrm{DMF}]_{0}=$ for bulk $83.50 / 1.00 / 0.18 / 3.85$ and for solution 83.50/1.00/0.18/15.40.

${ }^{\mathrm{a}, \mathrm{b}}$ Calculated from Eq. 1 

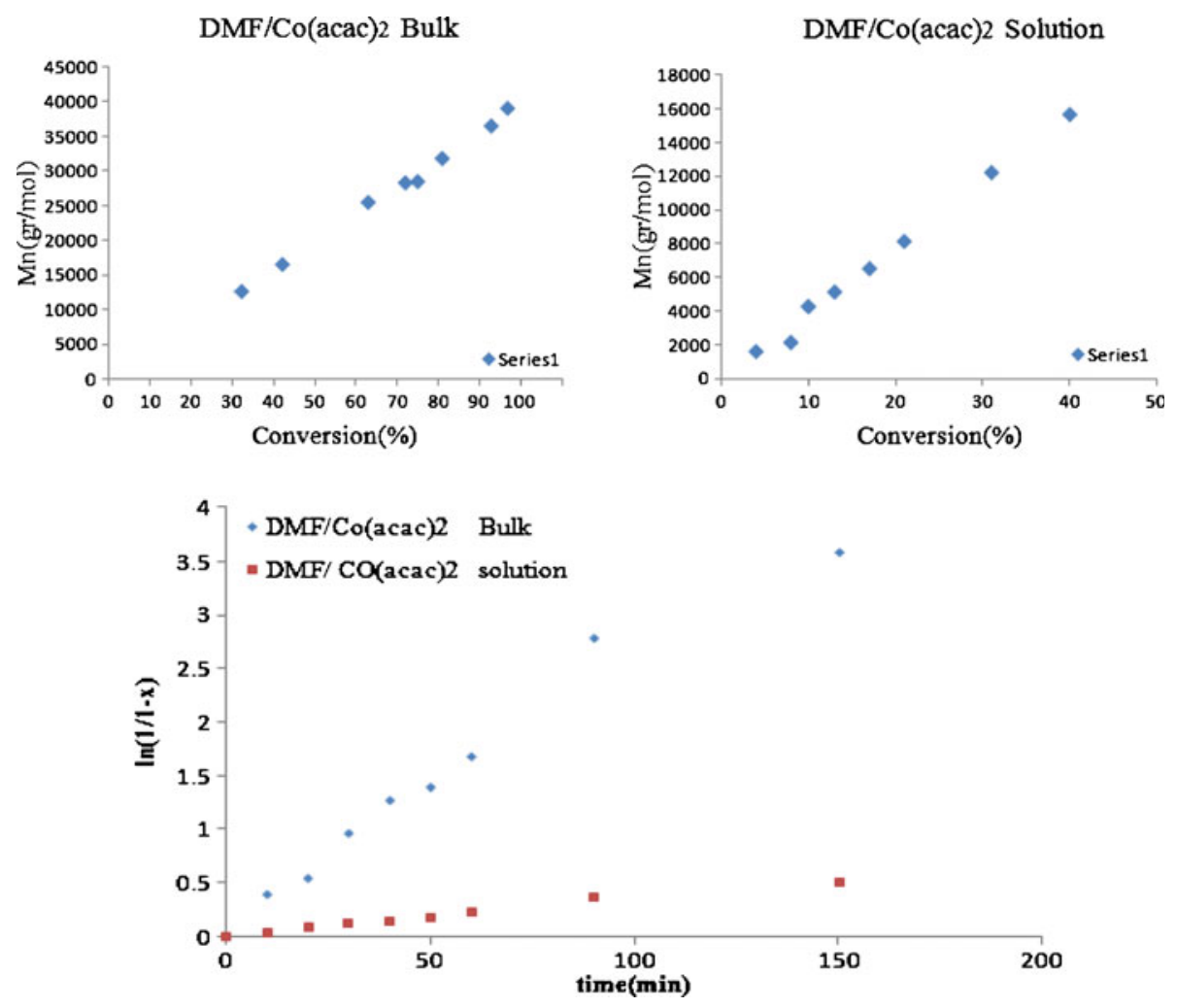

Figure 1. Time dependence of $\ln [\mathrm{M}]_{0} /[\mathrm{M}]$ (M: monomer); b) dependence of the polyvinyl acetate $\mathrm{Mn}$ on the monomer conversion for the $\mathrm{AN}$ polymerization initiated by $\mathrm{BPO}$ in $\mathrm{DMF}$ at $60^{\circ} \mathrm{C}$ in bulk $\left([\mathrm{VAc}]_{0} /[\mathrm{Co}]_{0} /[\mathrm{BPO}]_{0} /[\mathrm{DMF}]_{0}=83.50 /\right.$ $1.00 / 0.18 / 3.85)$ of and solution polymerization $\left([\mathrm{VAc}]_{0} /[\mathrm{Co}]_{0} /[\mathrm{BPO}]_{0} /[\mathrm{DMF}]_{0}=\right.$ 83.50/1.00/0.18/15.40).

adduct, which mimics the dormant species, namely the Co-capped short PVAc oligomer recently reported by us. $^{2}$ Indeed, using such a CMRP initiator in the absence of BZPO, the number of chains should be constant and provide linear plots of $\ln [\mathrm{M}]_{0} /[\mathrm{M}]$ versus time, and $\mathrm{M}_{\mathrm{n}}$ versus monomer conversion; as long as initiation is fast compared to propagation. A vinyl acetate homopolymerization experiment using this initiator was carried out in DMF at $60^{\circ} \mathrm{C}$, and the results are presented in figure 2. The polymerization start without induction period was observed (figure $2 \mathrm{~b}$ ), proving that the cobaltmediated vinyl acetate radical homopolymerization follows a reversible termination pathway. As expected, the kinetics were first order with respect to the monomer as assessed by the linear time dependence of the $\ln [\mathrm{M}]_{0} /[\mathrm{M}]$ function, suggesting that the number of radicals in the polymerization medium remained constant throughout the polymerization. As expected, the molar masses increased linearly with monomer conversion. To explain this profile, it is interesting to compare these results with those of the VAc polymerization. The CMRP of VAc conducted in bulk in the absence of any coordinating ligands showed a much longer induction time. The effect of DMF as a ligand is currently under investigation. ${ }^{8}$ The conversion in the bulk is $50 \%$ complete within 10 minutes. In the

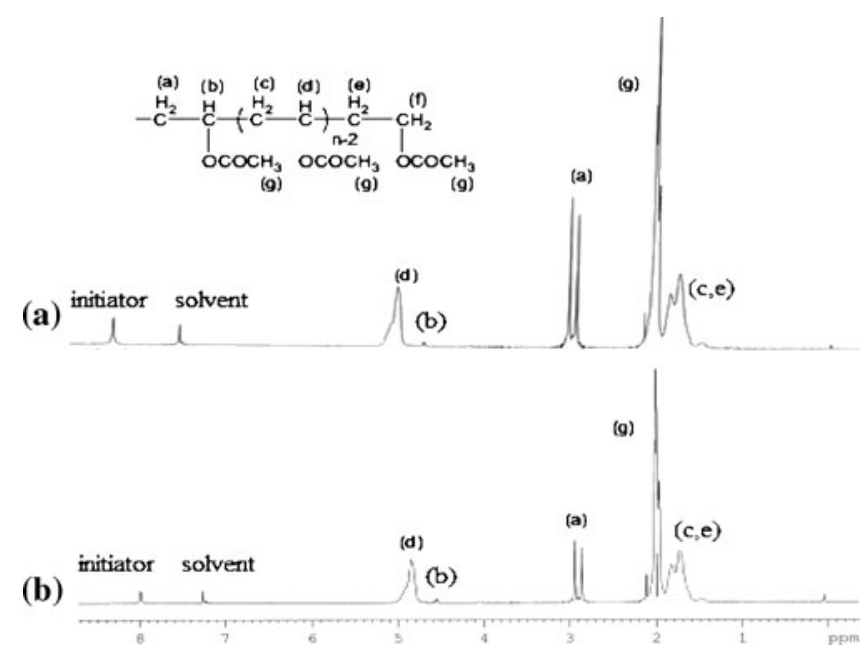

Figure 2. ${ }^{1} \mathrm{H}$ NMR a of PVAc produced from (a) bulk and (b) solution with $\mathrm{Co}(\mathrm{acac})_{2} / \mathrm{DMF}$ complex with $\mathrm{BPO}$ initiator. 
Table 2. Effect of DMF concentration in PVAc yield at $60^{\circ} \mathrm{C}\left([\mathrm{VAc}]_{0}=50 \mathrm{molL}^{-1}\right)$ at $\mathrm{t}=30 \mathrm{~min}$.

\begin{tabular}{lcc}
\hline Reaction & DMF concentration & Conversion\% \\
\hline 1 & 0.8 & 57 \\
2 & 0.6 & 61 \\
3 & 0.4 & 66 \\
4 & 0.2 & 81 \\
5 & 0.1 & 71 \\
6 & - & 40 \\
\hline
\end{tabular}

solution polymerization, DMF solvates the monomer and the diffusion mechanism is different from that observed in the bulk (see table 1). Contrary to solution polymerization reported, the reaction in the bulk is fast and it is complete (95\%) within 150 minutes with relatively narrow molecular weight distribution (PDI $=2.19$ ) for a high Mw of 45595. The molecular weight distribution of polymer during this reaction remains almost constant, which indicates that the reaction is almost controlled (see figure 1). The increase in polymerization reaction rate may be attributed to the diffusion of $\left[\mathrm{Co}(\mathrm{acac})_{2}\right]$ complex with DMF in the reaction and formation of stabilized monomer radical in bulk (see table 2).

\subsection{Structural analysis with ${ }^{1} H N M R$}

The microstructure of the PVAc in bulk and in solution is shown in figures $2 \mathrm{a}$ and $\mathrm{b}$. Typical signals of PVAc identified are methine protons d (4.6-4.9 ppm), methylene protons $\mathrm{c}, \mathrm{e}(1.7-1.9 \mathrm{ppm})$, methyl protons g (1.9 ppm), $\mathrm{OCH}_{3}(2 \mathrm{ppm}), \mathrm{CH}_{2}$ end groups (2.8$3 \mathrm{ppm})$, in $\mathrm{CDCl}_{3}(7.2 \mathrm{ppm}) .{ }^{1}$ From integration of $\delta$ : 2.8-3 ppm related to $\mathrm{CH}_{2}$ end groups and peak at $\delta$ : $2 \mathrm{ppm}$ related to $\mathrm{CH}_{3}$, the branching percentage of 9.32\% was estimated for PVAc in bulk polymerization (figure 2a). The calculated branching was $22.4 \%$ for PVAc in the solution (figure $2 b$ ).

\subsection{Thermal analysis}

Three distinct glass transitions are observed on the curve of PVAc, the first transition at about $31.5^{\circ} \mathrm{C}$ is due to the glass transition temperature of PVAc segment (Tg,PVAc) ${ }^{8}$ and the second at about $85^{\circ} \mathrm{C}$ corresponds to melting temperature of branching centers ( $\mathrm{Tg}$, branching centers) and the other at $122.8^{\circ} \mathrm{C}$ corresponds to melting temperature of linear polymer( $\mathrm{Tg}$, linear polymer)(see figure $3 \mathrm{a}$ and table 4$).{ }^{8}$ In bulk PVAc, four distinct glass transitions are observed which the first transition at about $97.7^{\circ} \mathrm{C}$ is due to the glass
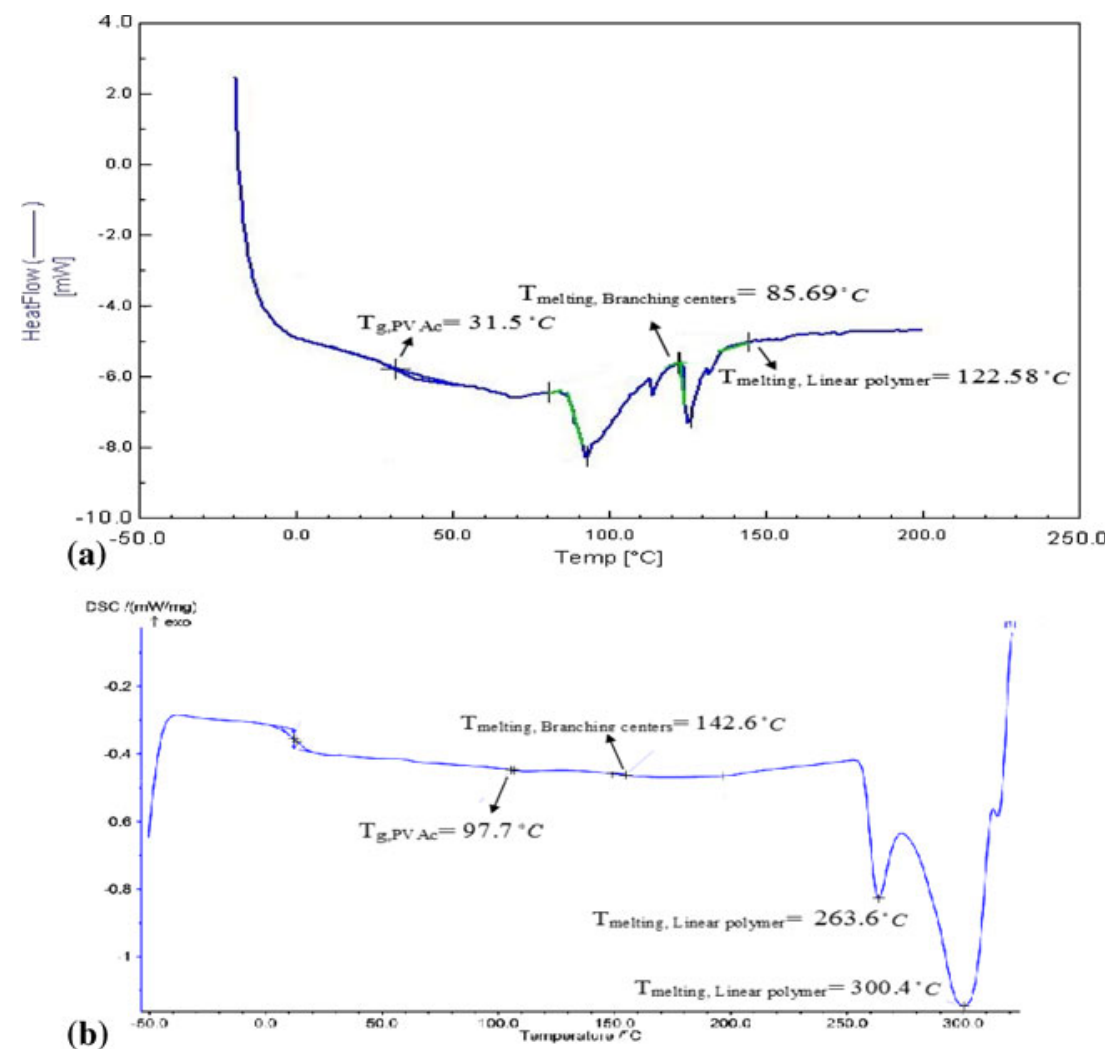

Figure 3. DSC of (a) PVAc, (b) bulk PVAc in capillary tube with $\mathrm{Co}(\mathrm{acac})_{2}$. 
Table 3. GPC of solution polymerization of PVAc in the presence of $\mathrm{DMF} / \mathrm{Co}(\mathrm{acac})_{2}$ at $60^{\circ} \mathrm{C}\left([\mathrm{VAc}]_{0}=50 \mathrm{molL}^{-1}\right)$.

\begin{tabular}{lcccc}
\hline No. & Time(h) & PDI & Conversion $\%$ & $\bar{M}_{n, G P C}(\mathrm{~g} / \mathrm{mol})$ \\
\hline 1 & 4 & 2.45 & 51 & 20600 \\
2 & 6 & 2.07 & 72 & 28200 \\
3 & 8 & 2.04 & 80 & 34600 \\
\hline
\end{tabular}

transition temperature of PVAc segment (Tg,PVAc), the second at about $142.6^{\circ} \mathrm{C}$ corresponds to melting temperature of branching centers ( $\mathrm{Tg}$, branching centers) and the other at $263.6^{\circ} \mathrm{C}$ and $300.4^{\circ} \mathrm{C}$ correspond to the possible catalyst present in PVAc, and the product with higher meltings. ( $\mathrm{Tg}$, linear polymer)(see figure $3 \mathrm{~b}$ and tables 3 and 4). ${ }^{8,12}$

\subsection{Polymerization of PVAc in the capillary system}

The bulk polymerization of PVAc with $\mathrm{Co}(\mathrm{acac})_{2} / \mathrm{DMF}$ catalyst provided a new route for the reaction in the capillary systems of about $2 \mathrm{~mm}$ diameter. The resulting transparent and dimensionally stable solid is shown in figure 4. In this process, the facile controlled polymerization of vinyl acetate with $60 \%$ conversion within a few minutes proves a practically useful method in formation process with this homogeneous catalyst. The fast diffusion of catalyst in the bulk of the softened polymer allows a fast diffusion needed for the completion of reaction from $60 \%$ to $95 \%$ after few hours.

The XRD of the solid polymer formed is shown in figure 4. A new broad peak at $2 \Theta=18-19$ in figure $4 \mathrm{~b}$ indicated the effect of extension and orientation on reformation of the polymer. The crystallinity resulted from twice stretching is about $20.70 \%$ (calculated by Xvision software). The ease of formation with the facile formability or memory in the extension makes this process applicable to control the orientation and crystallinity of polyvinyl acetate. It is observed that crystallinity strongly controls the permeability of oxygen and its transport may widen the low cost application of this polymer in the packaging area. It can also provide

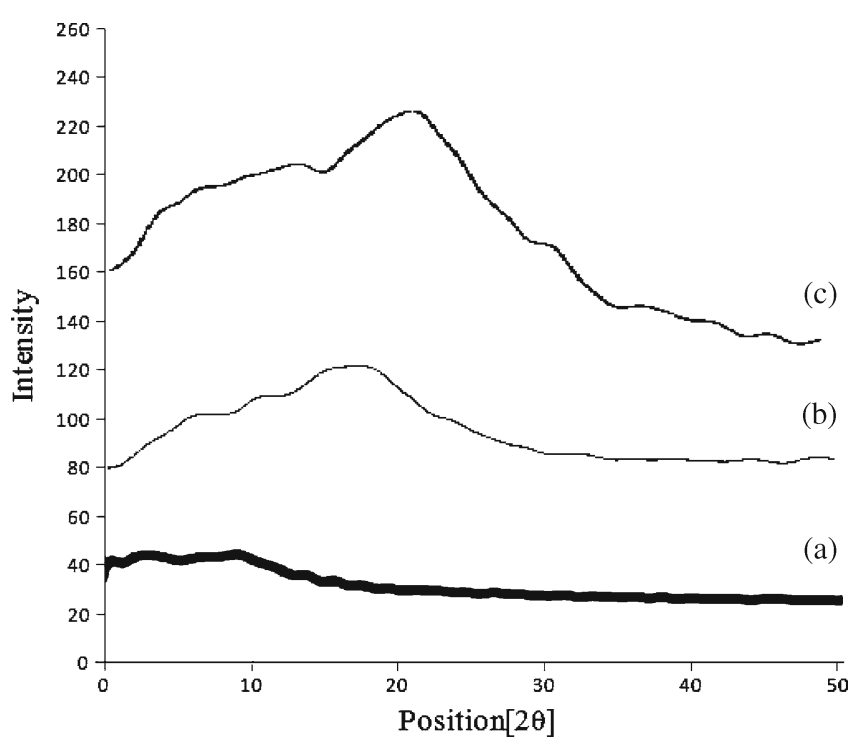

Figure 4. XRD of Bulk PVAc in (a) flask, (b) normal state in capillary tube and (c) stretched state in capillary tube.

not only a clean rout for formation of a new biodegradable processes but also to the hydrolysis of environmentally friendly polyvinyl alcohol in the film formations, separation and bioprocesses, or coatings (figure 4).

\section{Conclusion}

The cobalt-mediated controlled radical polymerization of vinyl acetate was studied in bulk. It indicated a faster rate than solution polymerization. The $\mathrm{Co}(\mathrm{acac})_{2} / \mathrm{DMF}$ catalyst controlled the radical polymerization of vinyl acetate. This route provides the synthesis of a welldefined PVAc solid structure without cobalt catalyst impurities, unreacted monomers, or the problems related to very low molecular and broad molecular weight distribution of the polymer. The rapidly initiated reaction with $\mathrm{Co}(\mathrm{acac})_{2} / \mathrm{DMF}$ with $\mathrm{BZPO}$ is complete within a few hours and the induction time is very small. Based on the high reactivity of the catalyst at moderately low temperatures, the reaction is without induction. The microdimensional stability of the solid formed in the capillary system suggested a controlled

Table 4. Thermal analysis of PVAc synthesized in bulk at 60 .

\begin{tabular}{lcccc}
\hline Reaction & $\mathrm{T}_{\mathrm{g}, \mathrm{PVAc}}\left[{ }^{\circ} \mathrm{C}\right]$ & $\mathrm{T}_{\mathrm{m} \text {, branching centers }\left[{ }^{\circ} \mathrm{C}\right]}$ & $\mathrm{T}_{\mathrm{m}, \text { linear polymer }}\left[{ }^{\circ} \mathrm{C}\right]$ & Branching percent $^{\mathrm{a}}$ \\
\hline $\mathrm{DMF} / \mathrm{Co}(\mathrm{acac})_{2}$ (Solution) & 31.58 & 85.96 & 122.58 & 9.32 \\
$\mathrm{DMF} / \mathrm{ZnCl}{ }_{2}$ (Solution) & 64.46 & - & 127.8 & 22.17 \\
$\mathrm{DMF} / \mathrm{SnCl}$ (Solution) & 78 & - & 152.8 & 33.36 \\
$\mathrm{DMF} / \mathrm{Co}(\mathrm{acac})_{2}$ (Bulk) & 97.7 & 142.6 & & 4.8 \\
\hline
\end{tabular}

${ }^{\mathrm{a}}$ Calculated from ${ }^{1} \mathrm{HNMR}$ 
radical polymerization of vinyl acetate. This process may be extended to new applications with a radical or controlled radical polymerization cost effectiveness.

\section{Supplementary information}

The electronic supporting information can be seen in www.ias.ac.in/chemsci.

\section{References}

1. Semsarzadeh M A and Abdollahi M 2008 Polymer 49 3060

2. Semsarzadeh M A and Abdollahi M 2011 Appl. Polym. Sci. In press.

3. Wakioka M, Baek K-Y, Ando T, Kamigaito M and Sawamoto M 2002 Macromolecules 35330
4. Semsarzadeh M A and Eshtad M 1997 Iranian Polymer Journal 6261

5. Matyjaszewski K and Davis T P 2002 Handbook of radical polymerization, (Hoboken, NJ: WileyInterscience)

6. Debuigne A, Michaux C, Jerôme C, Jerôme R, Poli R and Detrembleur C 2008 Chem. Eur. J. 147623

7. Pietrasik J, Hui C M, Chaladaj W, Dong H, Choi J, Jurczak J, Bockstaller M R and Matyjaszewsk K 2011 Macromol. Rapid Commun. 32295

8. Debuigne A, Caille J-R, Detrembleur C and Jerome R 2005 Angew. Chem. Int. Ed. 443439

9. Debuigne A, Caille J-R and Jerome R 2005 Angew. Chem. Int. Ed. 441101

10. Bryaskova R, Detrembleur C, Debuigne A and Jerome R 2006 Macromolecules 398263

11. Semsarzadeh M A, Mirzaei A, Vasheghani F M and Nekoomanesh H M 2003 Eur. Polym. J. 392193

12. Sandler S R 1992 Polymer synthesis (2nd edition) (New York: Academic Press) 